\title{
Relative Velocity of Accretion of Weight and Height Using the Benn Index in the First Nine Years of Life
}

\author{
PETER S. GARTSIDE, MARK S. DINE, and CHARLES J. GLUECK ${ }^{(19)}$ \\ Lipid Research Clinic and General Clinical Research Center, and the General Clinical Research Center CLINFO \\ Center, Departments of Medicine and Pediatrics, Lipid Research Division and Division of Epidemiology and \\ Biostatistics, University of Cincinnati Medical Center, Cincinnati, Ohio, USA
}

\begin{abstract}
Summary
Using the power ponderosity index of Benn, weight $(W) /$ height $(H)^{p},\left(W / H^{p}\right)$ where the value of $p$ is determined so that the correlation of height and $W / H^{p}$ is zero, a set of $p$ values was obtained from longitudinal data of 630 healthy, white, middle class children ranging in ages from birth to 9 years. Our data revealed two turning points in the relative velocity of change of height and weight not previously recognized by separate studies of velocity changes in weight and height related to chronological age. The value of $p$ increased from birth (1.72) until about 1 month (2.39) for girls, and 5 months for boys (2.30), the first turning point, and then fell to a nadir at age 18-21 months for girls (1.75) and 21-24 months for boys (1.73), the second turning point. This fall to the nadir represents the greater influence of velocity change in height over weight. From then to age 9 years, there was a gradual and steady increase in $p$, greater for girls than for boys, representing the greater influence of velocity change in weight over height. The values of $p$ have now been estimated for white, middle class children over the ages of birth to 9 years and may have utility in studies which compare obesity indicators.
\end{abstract}

\section{Abbreviations}

$W$, weight

$H$, height

$W / H^{p}$, Benn's power index

The two most easily measured and relatively accurate clinical indices of growth, $W$, and $H$ are only indirect measurements of relative fatness $(6,9,13)$. The direct methods of determining relative fatness include somatotyping, skinfold measurements, hydrostatic determinations of density, and chemical isotope dilution. All have limitations or cannot be done in clinical practice $(4,9,13)$. The indirect methods designed to quantitate relative ponderosity include calculating relative weight for height, or some power function of height, $\left(W / H, W / H^{2}, W / H^{1 / 3}\right)(4,9)$. The calculations of $W / H, W / H^{2}, W / H^{1 / 3}(4,9)$ are performed in an attempt to limit the correlation of weight to height $(1,4)$, but they fail to do so $(4,8)$. The best indirect index would be one that has no correlation to height $(1,5,9,10)$. The use of a power index to determine relative fatness of children is further complicated by the progressive and expected changes in height from infancy to the end of adolescence.

To overcome these limitations, Benn (1) has proposed the use of a power index, $W / H^{p}$, where the exponent $p$, not limited to whole numbers, is that power of $H$, which enables the correlation between the ratio $W / H^{p}$ and the height to be zero. In the equation of Benn, $b=p \bar{w} / \bar{h} ; \bar{w}$ and $\bar{h}$ are the average height and weight: for the age groups being considered, and $b$ is the slope of Benn's arithmetic regression model, i.e., $d W / d H$. This can be rewritten as $(d W / d t) /(d H / d t)$, the relative velocity of height and weight.

Thus, examination of Benn's Figures 1 and 2 (1) which plot. the slope of $b$ (or $p$ ) against weight and height demonstrates that as the value of the slope increases, the relative importance of weight gain becomes greater. Conversely, as the value of the slope decreases, the relative importance of height gain becomes greater. Thus, in growing children, changes in $p$ or $b$ represent changes in relative velocity of height and weight change.

We have longitudinally followed and reported upon a relatively homogeneous population of 630 children from birth to 9 years of age who are white, middle class, suburban, and have received both nutritional supervision and measurements by the same pediatrician (3). The absence of malnutrition, child neglect and/ or abuse, and the stable longitudinal follow-up of this cohort allowed evaluation of relative velocity of accretion of weight and height, with limited confounders, in healthy children. We do not know, however, how well our estimates of $p$ and $b$ can be generalized to biracial and/or low socioeconomic status groups of children. The purpose of our current report on this cohort, using paired height and weight data, is to calculate the changes in the value of $p$ and $b$ over the first 9 years of life, to better assess the relative velocity of height and weight change.

\section{MATERIALS AND METHODS}

The 630 children for study were selected from a middle class private practice (3); the data were obtained with informed consent. The methods of selection, the means of measurement, the transcription on the computer tape, and the methods of statistical analysis have previously been described (3). The set of children was selected for the study using the following criteria. 1) They had been seen for routine child health care from birth, in a single suburban pediatric practice. 2) They weighed more than $5 \frac{1}{2} \mathrm{lb}$ at birth. 3) They had no chronic or congenital illness that would affect normal gain in height and weight. 4) They were white children in the middle to upper-middle social class. 5) They were in the current files of the practice in September 1975. Infants were measured for both height and weight on an office platform scale graduated in pounds and inches. Infants were totally undressed, including diaper, for each weight measurement. Weight was measured to the quarter ounce. Length was noted to the nearest quarter inch using horizontal bars for both head and feet.

By age 2, the children were studied standing on a scale that measured both height and weight. Older children wore only underpants when weighed. Since all of the children had height 
and weight measurements done in a consistent manner by a single pediatrician in a stable practice setting (3), interobserver variance in measurement error should be at a minimum, allowing more stable estimates of $p$ and $b$.

The exponent $p$ of the formula of Benn (1), $W / H^{p}$, was determined for selected ages, so that the correlation of height and $W / H^{p}$ was zero. This was done for each of 21 ages ranging from birth to $108+$ months of age (Figs. 1 and 2) (Table 1), separately for boys and girls. Birth measurements included birth to 15 days of life; age 1 month (15-45 days); age 2 months (4575 days), etc., up to and including age 5 months. From 6 months on, the segment method was used, as described previously (3).

In addition to $p$, the slope $b$ was also calculated at each age using the formula described by Benn (1), $b=p \bar{w} / \bar{h}$, where $\bar{w}, \bar{h}$ are the average height and weight for the age groups being considered (Fig. 3, Table 1).

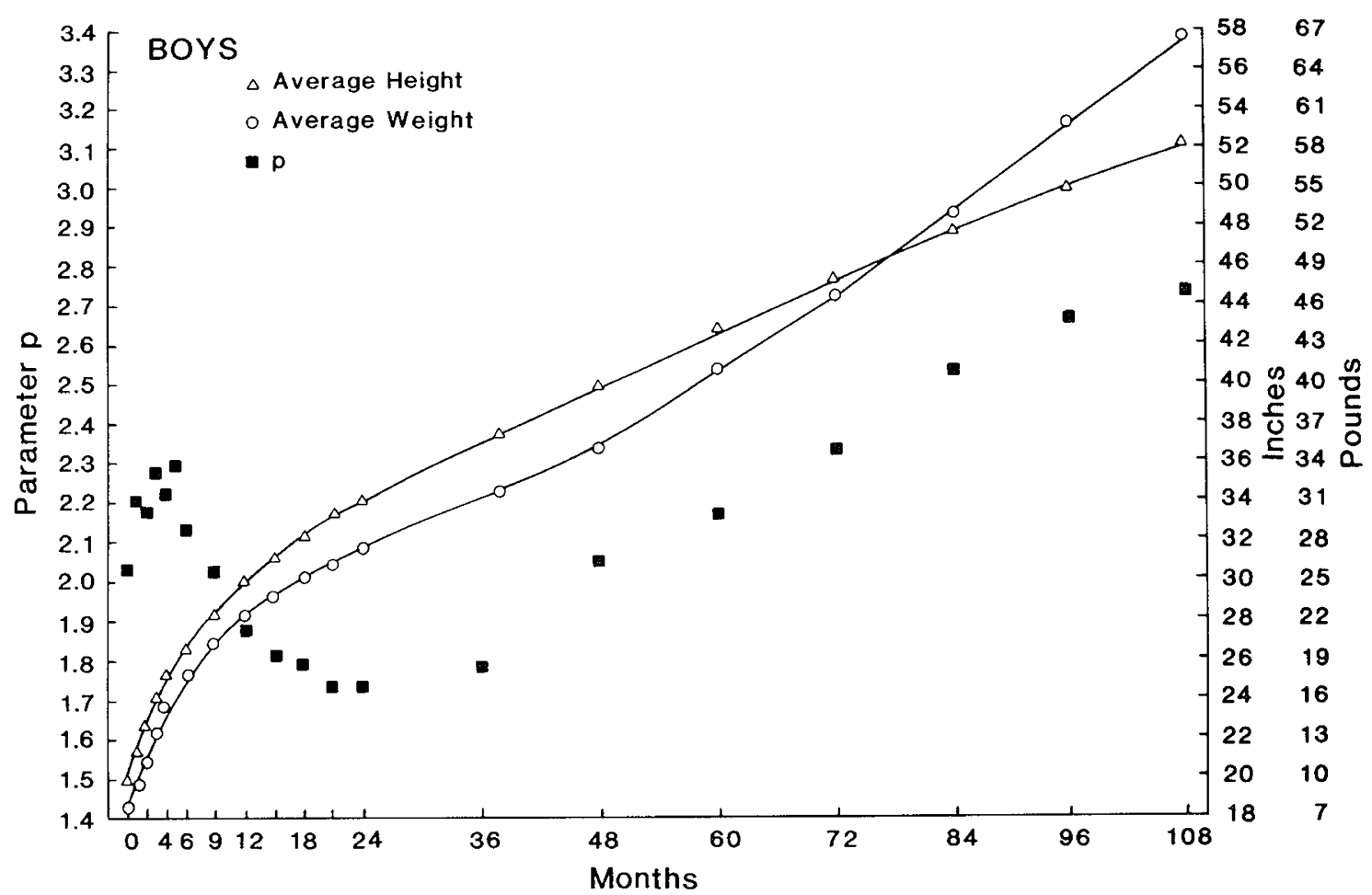

Fig. 1. Values of parameter $p$ of Benn's index $\left(W / H^{p}\right)$ from birth to 9 years for white healthy boys, where $p$ is the slope of the logarithmic regression model of Benn (1). Average height and weight changes are also displayed.

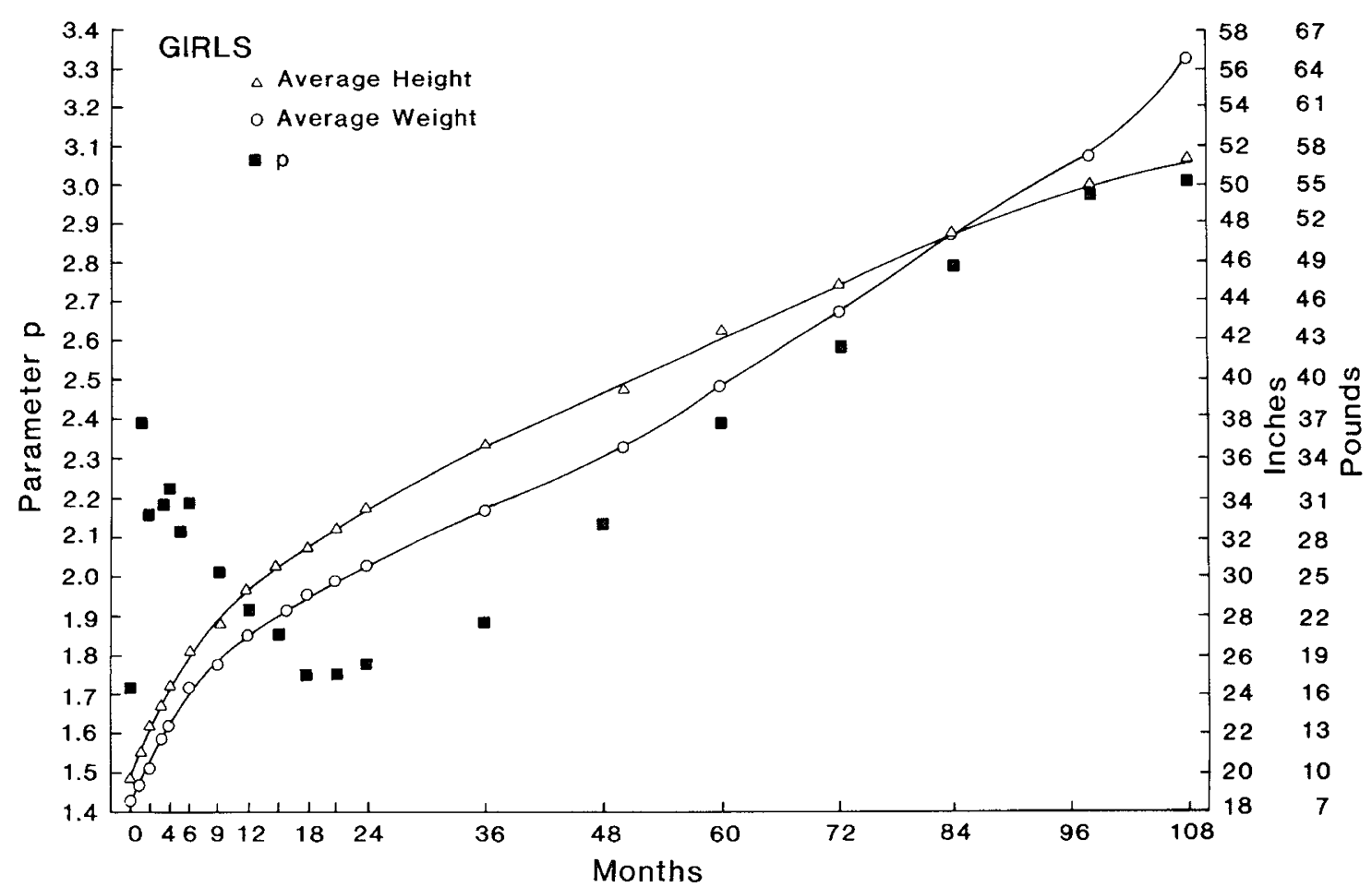

Fig. 2. Values of parameter $p$ of Benn's Index $\left(W / H^{p}\right)$ from birth to 9 years for white healthy girls, where $p$ is the slope of the logarithmic regression model of Benn (1). Average height and weight changes are displayed. 
Thus, substituting in the equation $b=p \times \bar{w} / \bar{h}$ using the data on 3-month-old boys from Tables 1 and 2 as an example yields the identity $1.29=2.27 \times 13.7 / 24.09$. According to the two models given in Benn (1) which relate to height and weight, $p$ represents the slope of the logarithmic regression model, and $b$ is the slope of the arithmetic regression model.

\section{RESULTS}

The data represent 9,448 paired height and weight measurements of 630 white, middle class children from a single surburban

Table 1. Values of the parameters $\mathrm{p}$, and $\mathrm{b}$ by age and sex of Benn's index (I) $\overline{\mathrm{W}} / \overline{\mathrm{H}}^{\mathrm{p}}$ and $\mathrm{p}=\mathrm{b}(\overline{\mathrm{H}} / \overline{\mathrm{W}})$

\begin{tabular}{|c|c|c|c|c|c|c|}
\hline \multirow{2}{*}{$\begin{array}{c}\text { Age } \\
\text { (months) }\end{array}$} & \multicolumn{2}{|c|}{$p$} & \multicolumn{2}{|r|}{$b$} & \multicolumn{2}{|r|}{$n$} \\
\hline & Males & Females & Males & Females & Males & Females \\
\hline Birth & 2.04 & 1.72 & 0.77 & 0.64 & 261 & 271 \\
\hline 1 & 2.21 & 2.39 & 0.97 & 1.01 & 270 & 278 \\
\hline 2 & 2.18 & 2.15 & 1.12 & 1.04 & 303 & 320 \\
\hline 3 & 2.27 & 2.17 & 1.29 & 1.16 & 309 & 321 \\
\hline 4 & 2.23 & 2.23 & 1.35 & 1.27 & 309 & 321 \\
\hline 5 & 2.30 & 2.12 & 1.46 & 1.27 & 309 & 321 \\
\hline 6 & 2.13 & 2.19 & 1.41 & 1.36 & 309 & 321 \\
\hline 9 & 2.03 & 2.02 & 1.45 & 1.36 & 309 & 321 \\
\hline 12 & 1.88 & 1.93 & 1.40 & 1.36 & 308 & 321 \\
\hline 15 & 1.81 & 1.85 & 1.37 & 1.34 & 307 & 319 \\
\hline 18 & 1.78 & 1.75 & 1.38 & 1.29 & 307 & 319 \\
\hline 21 & 1.73 & 1.75 & 1.37 & 1.32 & 306 & 319 \\
\hline 24 & 1.73 & 1.77 & 1.39 & 1.37 & 306 & 319 \\
\hline 36 & 1.79 & 1.88 & 1.54 & 1.56 & 306 & 315 \\
\hline 48 & 2.05 & 2.14 & 1.87 & 1.89 & 303 & 313 \\
\hline 60 & 2.16 & 2.38 & 2.09 & 2.23 & 286 & 296 \\
\hline 72 & 2.33 & 2.57 & 2.40 & 2.56 & 241 & 242 \\
\hline 84 & 2.53 & 2.79 & 2.81 & 2.99 & 202 & 204 \\
\hline 96 & 2.66 & 2.97 & 3.18 & 3.42 & 168 & 173 \\
\hline 108 & 2.73 & 3.04 & 3.50 & 3.80 & 140 & 138 \\
\hline
\end{tabular}

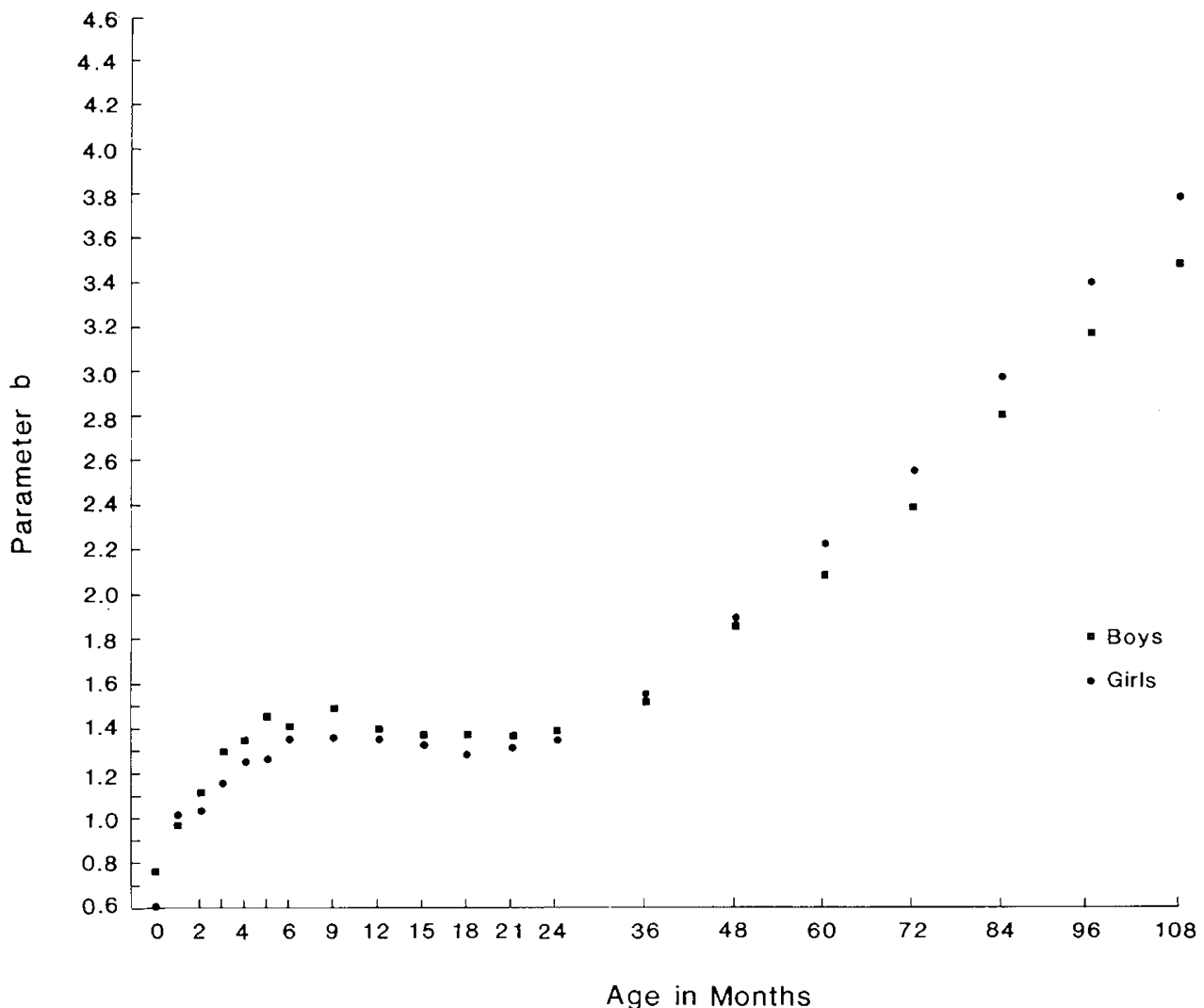

Fig. 3. Values of the parameter $b$ of Benn's formula $b=p \bar{w} / \bar{h}$ by sex and by age from birth to 9 years for white healthy children, where $b$ is the slope of the arithmetic regression model of Benn (1). pediatric practice. Six hundred one children were followed for 5 years, and 279 were followed for at least 9 years.

The values of $p$ and $b$ are displayed in Figures 1-3 and Table 1. The values of $p$ change constantly throughout the 9 years of study. At birth, boys and girls have widely differing values of $p$ 2.04 and 1.72 , respectively. At 1 month values have risen to 2.21 and 2.39 , an $8.3 \%$ increase for boys (Fig. 1) and a $39 \%$ increase for girls (Fig. 2). Values for girls decline from this point but those for boys increase to 2.30 at age 5 months (a maximum $12.7 \%$ rise) before declining. The nadir for boys is reached at 21-24

Table 2. Mean values of height (inches) and weight (pounds) by

\begin{tabular}{|c|c|c|c|c|c|c|}
\hline \multirow{2}{*}{$\begin{array}{c}\text { Age } \\
\text { (months) }\end{array}$} & \multicolumn{3}{|c|}{ Males } & \multicolumn{3}{|c|}{ Females } \\
\hline & $\bar{H}$ & $\bar{W}$ & $n$ & $\bar{H}$ & $\bar{W}$ & $n$ \\
\hline Birth & 19.99 & 7.52 & 261 & 19.65 & 7.26 & 271 \\
\hline 1 & 21.48 & 9.40 & 270 & 21.12 & 8.91 & 278 \\
\hline 2 & 22.86 & 11.73 & 303 & 22.41 & 10.83 & 320 \\
\hline 3 & 24.09 & 13.70 & 309 & 23.53 & 12.53 & 321 \\
\hline 4 & 25.16 & 15.28 & 309 & 24.55 & 13.98 & 321 \\
\hline 5 & 26.06 & 16.60 & 309 & 25.40 & 15.19 & 321 \\
\hline 6 & 26.83 & 17.77 & 309 & 26.12 & 16.23 & 321 \\
\hline 9 & 28.57 & 20.44 & 309 & 27.86 & 18.71 & 321 \\
\hline 12 & 30.01 & 22.28 & 308 & 29.31 & 20.59 & 321 \\
\hline 15 & 31.21 & 23.68 & 307 & 30.51 & 22.05 & 319 \\
\hline 18 & 32.27 & 25.02 & 307 & 31.63 & 23.53 & 319 \\
\hline 21 & 33.22 & 26.25 & 306 & 32.61 & 24.65 & 319 \\
\hline 24 & 34.06 & 27.45 & 306 & 33.49 & 25.85 & 319 \\
\hline 36 & 37.05 & 31.88 & 306 & 36.62 & 30.36 & 315 \\
\hline 48 & 39.89 & 36.34 & 303 & 39.52 & 34.92 & 313 \\
\hline 60 & 42.70 & 41.26 & 286 & 42.24 & 39.50 & 296 \\
\hline 72 & 45.32 & 46.73 & 241 & 44.86 & 44.73 & 242 \\
\hline 84 & 47.72 & 53.06 & 202 & 47.31 & 50.68 & 204 \\
\hline 96 & 49.98 & 59.70 & 168 & 49.55 & 57.08 & 173 \\
\hline 108 & 52.16 & 66.97 & 140 & 51.75 & 64.69 & 138 \\
\hline
\end{tabular}


months ( $p=1.73$ ), the nadir for girls at $18-21$ months ( $p=$ 1.75). The values for boys rise gradually to 2.69 at 9 years of age and to 3.04 for girls (Figs. 1 and 2, Table 1).

At birth, boys and girls have widely differing values of $b, 0.77$ and 0.64 . By 5 months, the value of $b$ for boys rose to 1.46 , declined to 1.37 by 21 months, and gradually rose to 4.34 after 9 years of age (Fig. 3). By 6 months, the value of $b$ rose to 1.36 for girls, remained generally level until age 36 months, and then rose to 4.52 after 9 years of age.

The shifting nature of the $p$ values cannot be appreciated from an inspection of the changes in average height and weight over time (Figs. 1 and 2).

\section{DISCUSSION}

During the first 9 years of life, height and weight are constantly increasing. The velocity of gain in height $(\Delta H / \Delta t)$ is constantly decreasing $(12,16)$. The velocity of gain in weight $(\Delta W / \Delta t)$ decreases rapidly until age 2 and then increases over the subsequent 9 years $(12,16)$. The value of $p$ of Benn's power index, $W / H^{p}$ (1) changes direction twice, increasing for 1 month after birth in girls, and for 5 months in boys, decreasing to a nadir at age 2 years, and increasing steadily thereafter. The increases in $p$ reflect the greater influence of relative weight velocity; decreasing values of $p$ represent the period of growth reflecting the greater influence of relative height velocity.

We have described the numerical values and the changes in the exponent $p$ of the power index $W / H^{p}$ of Benn (1), the ponderosity index least correlated with height, and $b$, the gradient between height and weight. By using either index ( $p$ or $b$ ), comparisons of populations of children, but not individual children, may be made more accurately when assessing factors associated with obesity or relative fatness.

We speculate that the change in $p$, peaking during the 1st and 5th months of life and then falling, reflects the ending of the influence of the prenatal environment $(14,17)$, and the emergence of genetic and postnatal environmental factors, primarily growth hormone, insulin, and cortisol. These three hormones are major determinants of the utilization of ingested nutrients (11). We cannot explain the early difference in rate of change of boys and girls.

The fall in $p$ between the neonatal period and the end of the 2 nd year of life, reflecting the greater influence of relative height velocity over weight, suggests the predominance of hypothalamic control via secretion of growth hormone-releasing factor and increments in growth hormone (2). After the nadir in $p$ is reached at 18-24 months, the relative predominance of accretion in weight occurs because of the preponderant action of somatomedin and insulin (2).

Previous separate assessment of velocity change of height and weight $(12,16)$ have not implicated potential changes in the timing of hypothalamic control. Our current observations might serve as a time frame in which to assess variations in hypothal- amic activity during accretion of height and weight, and may be two timing points in the series of hypothalamic clocks suggested by Tanner (15).

If there is a critical time in body growth that determines eventual outcome, it may be during this 2-24-month period where tissue hyperplasia is occurring more rapidly than increase in size of cells (11).

Using these values of $p$ may improve the correlation between indirect, Benn index (1), and direct measures (skinfold, densitometric, or isotope dilution) of relative fatness, but assessments of these correlations were beyond the scope of this study.

\section{REFERENCES AND NOTES}

1. Benn RT 1971 Some mathematical properties of weight-for-height indices used as measures of adiposity $\mathrm{Br} \mathrm{J}$ Prev Soc Med 25:42

2. Daughaday WH 1981 Growth hormone and the somatomedins. In: Daughaday WH (ed): Endocrine Control of Growth. Elsevier, Inc, New York, p 121

3. Dine MS, Gartside P, Glueck CJ, Rheines L, Greene G, Khoury P 1979 Where do the heaviest children come from? A prospective study of white children from birth to five years of age. Pediatrics 63:1

4. DuRant RH, Linder CW 1981 An evaluation of five indexes of relative body weight for use with children. J Am Diet Assoc 78:35

5. Frisancho AR, Flegel PN 1982 Relative merits of old and new indices of body mass with reference to skinfold thickness. Am J Clin Nutr 36:697

6. Garn SM, Pesick SD 1982 Comparison of the Benn index and other body mass indices in nutritional assessment. Am J Clin Nutr 36:573

7. Knowler WC, Garrow J 1982 Obesity indices derived from weight and height. Int J Obesity 6:241

8. Lee J, Kolonel N, Hinds MW 1982 The use of inappropriate weight-height derived index of obesity can produce misleading results. Int J Obesity 6:233

9. Lee J, Kolonel LN, Hinds MW 1981 Relative merits of the weight-correctedfor height indices. Am J Clin Nutr 34:2521

10. Lee J, Kolonel LN, Hinds MW 1982 Relative merits of old and new indices of body mass: a commentary. Am J Clin Nutr 36:727

11. Philips LS 1981 Nutrition, metabolism and growth. In: Daughaday WH (ed): Endocrine Control and Growth. Elsevier, Inc, New York p 1

12. Pomerance HH, Krall JM 1981 Linear regression to approximate longitudinal growth curves: Revised standards for velocity of weight and length in infants. Pediatr Res 15:1390

13. Roche AF, Siervogel RM, Chumlea WC 1981 Grading body fatness from limited anthropometric data. Am J Clin Nutr 34:2831

14. Tanner JM 1962 Growth at Adolescence, ed 2. Charles C Thomas Co, Springfield, IL, p 120

15. Tanner JM 1962 Growth at Adolescence, ed 2. Charles C Thomas Co, Springfield, IL, p 238-239

16. Tanner JM, Whitehouse RH, Takaishi M 1966 Standard from birth to maturity for height, weight, height velocity and weight velocity: British children. Arch Dis Child 41:613

17. Widdowson EM 1975 Maternal nutrition and somatic development of the fetus. Nutrition, growth, and development. In: Canosa CA (ed): Modern Problems in Paediatrics. Karger, Basel vol 14, p 68

18. This investigation was supported by Lipid Research Clinic N01 HV-2914-L, by General Clinical Research Center Grant RR00068-20, and by General Clinical Research Center CLINFO Grant RR00068-2-5. This protocol was approved by the University of Cincinnati Faculty Committee on Human Research.

19. Requests for reprints should be addressed to: Dr. C. J. Glueck, General Clinical Research Center, University Hospital, Mail Location 767, Cincinnati, OH 45267.

20. Received for publication June 16, 1983

21. Accepted for publication September 19, 1983. 